\title{
Mythological foundations of ontology
}

\section{[Мифологические основания онтологии]}

\author{
Svetlana V. Potapova - Irina Yu. Danilova - Valeriy I. Prasolov - Elena V. \\ Makarova - Nina I. Kryukova
}

DOI: 10.18355/XL.2018.11.02.53

\begin{abstract}
The relevance of the problem is due to contradictions between the mythological prerequisites of ontology, considered as an integral part of social life, and the expansion of ideas about the myth at the beginning of the XXI century, the enrichment of knowledge about its functions, structure, and relationships with the individual psychology of human creativity. The purpose of the article is to reveal the mythological foundations of ontology, to determine the role of mythological consciousness in the development of cultural and social life, to identify certain elements of mythology and myth-making, which are actual or potential prerequisites of philosophical ontology. The leading method of studying this problem is the method of comparative-typological analysis, system-structural approach, the principles of dialectics, understood as a philosophical doctrine of the interaction of opposites, universal connection, and development, as well as the principle of unity of historical and logical. At the same time, General scientific methods of cognition were used.

Key words: mythological foundations of ontology, mythological consciousness, myth, mythological worldview
\end{abstract}

\begin{abstract}
Аннотация
Актуальность исследуемой проблемы обусловлена противоречиями между мифологическими предпосылками онтологии, рассматриваемыми как неотъемлемая часть общественного бытия, и расширением представлений о мифе в начале XXI века, обогащением знаний относительно его функций, структуры и связей с индивидуальной психологией творчества человека. Цель статьи заключается в раскрытии мифологических оснований онтологии, определении роли мифологического сознания в развитии культурной и общественной жизни, выявлении определённых элементов мифологии и мифотворчества, являющихся актуальными или потенциальными предпосылками философской онтологии. Ведущим методом исследования данной проблемы является метод сравнительно-типологического анализа, системно-структурный подход, принципы диалектики, понимаемой как философское учение о взаимодействии противоположностей, всеобщей связи и развития, а также принцип единства исторического и логического. В то же время были использованы общенаучные методы познания: анализ и синтез, восхождение от абстрактного к конкретному, применялись идеи философской герменевтики. В статье раскрыто содержание понятия мифотворчества с учётом онтологической составляющей; выявлены элементы, служащие мифологическими основаниями содержания философской онтологии; проведён методологический анализ содержания мифологической картины мира, выявлена мифологическая предпосылочность категориального ряда онтологии, проанализировано соотношение мифотворчества и генезиса философии в их логической взаимосвязи.
\end{abstract}

Ключевые слова: мифологические основания онтологии, мифологическое сознание, миф, мифологическое мировоззрение 


\section{Introduction}

Исследования вопросов мифологии, где она выступает в качестве основного объекта изучения, позволили накопить достаточно богатый опыт в теоретическом освоении аспектов мифа. Миф представлял собой особую форму мировоззрения древних людей. В нем сочетались зачатки научных знаний, нормы человеческого поведения, религиозные представления, художественноэстетические образы объяснить особенности этого феномена.

Исследования последних десятилетий показали устойчивость мифологии, проходящей через всю историю различных обществ. Мифология является принадлежностью не только первобытных народов или же ранних, архаичных культур. Не завершается она и в рамках того типа сознания, который относится к классическим периодам истории, где мифология уже встроена в более развитую, чем она сама, духовную систему. Миф живет, умирает, возрождается вновь, и как форму освоения жизни его невозможно устранить.

Живучесть и устойчивость мифологического сознания, проявляющего себя в более развитых построениях (религия, идеология, философия и художественное творчество), вызвали к жизни концепции, раскрывающие определенные основы социального бытия и человеческой психики, в глубинах которых происходит формирование исходных элементов культуры.

Психоанализ рассматривал миф через одно из его главных свойств символичность как порождение индивидуального (Freud, 1992) или коллективного бессознательного, как «архетипический образ», возникающий вследствие опосредствования человеческим сознанием глубинных императивов родового прошлого. Символистика Фрейда заключена в сфере бессознательного, являясь необъяснимым выражением во вне этой непознаваемой, неизменной и в высшей степени таинственной психологической сущности. Фрейд предлагает способ расшифровки символики сновидений, названный им психоанализом. Он считает, что психоанализ пригоден и для расшифровки мифологической символики, поскольку миф, по его мнению, есть продукт бессознательного коллективного творчества: в своих сновидениях и фантазиях человек опускается на старую, архаическую ступень мышления и до деталей воспроизводит древние мифы и космогонии, древние жизненные ситуации (Freud, 2003).

По убеждению К.Г. Юнга (Jung, 1991), мир культуры тесно связан с человеческой природой и ее вечными символами, выражающимися в религиозно-мифологических представлениях. В отличие от Фрейда, он исходил из идеи коллективного бессознательного и символической интерпретации мифа. Символическая концепция мифа Юнга значительно отличается от собственно символической в смысле философской постановки проблемы символической структуры как специфической сущности мифа (Jung, 1991).

Мифологическое мышление является центральным понятием в концепции Э. Кассирера (Cassirer, 2001), где структуры мифа ограничиваются от научного способа познания: вмешательству и возобновлению мифа в сфере науки лишь тогда может быть успешно положен предел, если миф предварительно осознан в его собственной сфере в смысле того, чем он интеллектуально является и каковы его интеллектуальные возможности. Действительное преодоление мифа должно основываться на его познании и признании: лишь путем анализа его интеллектуальной структуры поддаются определению, с одной стороны, его специфический смысл, а с другой - его пределы. При определении структуры мифа Е. Кассирер (Cassirer, 2001) считает, что формы сознания сами «обнаружат масштаб и критерий истинности», т.е. в них действует «саморазвертывающийся дух». Отмечается, что формы сознания не являются «простыми копиями», в них выражается «первичный способ и направление оформление понятий».

XLinguae, Volume 11, Issue 2, April 2018, ISSN 1337-8384, eISSN 2453-711X 
А.Ф. Лосев (Losev, 1994) понятие «миф» органично связывал с понятием символа. Он доказывал, что миф есть символ в меру того, что, во-первых, «он есть просто вещь или существо», во-вторых, «он есть личность», в-третьих, «он есть история», в-четвертых, «в меру своей чудесности». По утверждению Лосева, миф символичен потому, что в нем содержится общая идея подобная живому существу, которое бесконечно в своих возможностях. Поэтому миф является моделью бесконечных порождений, отождествляемых с миром. Однако существуют символы, не являющиеся мифами. Таковы художественные образы, сравнительно редко становящиеся мифами. Тем не менее, «символ в конкретных произведениях науки и искусства может близко подходить к мифу и даже сливаться с ним» (Losev, 1995).

Некоторые элементы мифологии исторически были положены в качестве основы онтологических категорий в составе философских учений, приходящих на смену мифологическому мировоззрению. Исследователи указывают на своеобразное мировоззрение людей древних времен - «первобытный синкретизм», обозначающий слитность, нерасчлененность знаний, эмоций и действий, причины которого кроются в изначальных особенностях мышления этих людей: антропоморфизме и символизме. Те же самые особенности лежат и в основе мифологических представлений, составляющих сущность мировоззрения древних людей.

Роль древнего мифа, в частности, в виде содержащихся в мифах универсалий культуры, в дальнейшем развитии философии рассматривается исследователями с разных позиций. Ряд гипотез утверждает миф как непосредственную предпосылку возникновения философии, другие ученые склонны к позиции демифологизации мифа, представляющей собой преодоление мифических представлений. Так, Ф.Х. Кессиди (Cassidy, 2003) указывает, что возникновение философии из мифа и религии означало «не рационализирование фантастических религиозно-мифологических представлений, а отделение и размежевание от них, преодоление и критику их, зарождение нового типа мышления и новой ориентации в мире» (Cassidy, 2003). Его позиция указывает на то, что философское преодоление мифа сочетало и признание, и познание этого мифа: одни элементы мифа сохранялись, другие подвергались предметной критике, так что происходило интеллектуальное осмысление мифа и установление его пределов (Cassirer, 2001). Критике подвергались мифологические персонажи, отсутствующие в реальном жизненном опыте людей, в результате чего значительно сужался предмет мифологической веры. Процесс сужения предмета веры происходил крайне медленно, но, тем не менее, он был крайне необходим для развития духовной культуры и практической деятельности человека.

Убедителен вывод В.M. Найдыша (Naidysh, 2002) о неразвитости критическирефлексивной стороны в мифомышлении, отмечая, что мышление «оперирует со свойствами вещей, которые от самих вещей уже абстрагированы и выражены в образе, но оно еще не умеет выделить в содержании образа существенное и несущественное, закономерное и второстепенное, случайное и необходимое и связать их соответственно тому, как они сами связаны в объекте» (Naidysh, 2002).

Проведенные исследования часто не удовлетворяют требованиям логической завершенности. Остается не вовлеченным в круг дискуссий сам феномен «мифологической картины мира» с точки зрения ее предпосылочности для философии. Данная тема до сих пор не составляла предмета специального философского рассмотрения с привлечением материалов целого ряда смежных наук. Проблематика «мифологической картины мира» является значимой по той причине, что эта картина, с одной стороны, опосредует философские идеи и 
теории, a c другой - открывает перспективы для разработки онтологизированных образов на этапе ее реконструкции.

Таким образом, остается спорным и невыясненным ряд многих методологических вопросов, в том числе о сущности мифологии, ее месте в общественном сознании и социальных функциях. Возникает необходимость научного осмысления мифологических оснований в онтологии.

\section{Методологические основания и подходы}

Теоретическим основанием исследования являются принципы диалектики, понимаемой как философское учение о взаимодействии противоположностей, всеобщей связи и развития, а также принцип единства исторического и логического. Методологическую основу исследования составили системноструктурный подход и метод сравнительного анализа. Широко использовались идеи философской герменевтики, общенаучные методы познания: анализ и синтез, единство логического и исторического, восхождение от абстрактного к конкретному.

Методологический анализ содержания мифологической картины мира предполагает осмысление мифологического материала с точки зрения его онтологического потенциала, установление преемственной связи между мифами и древней философией, признанной рядом ученых. Эмпирической базой исследования служат мифы ряда народов Древнего мира, в особенности древних греков. Для изучения связи философии и мифологического феномена на основе реконструкции мифологического мышления привлекался материал мифологии и более поздних этнических образований, в частности, фольклор финно-угорских народов.

Порожденная на базе рационализации мифов философия явилась вместе с тем ничем иным, как философией мифологии. Мифологическое объяснение мира служит одновременно утверждением необходимости именно такого устройства, какое уже существует в мире. Содержание древних мифов естественно рассматривать в связи с его основополагающим строением. В нем выделяется описание того, откуда мир появился, как он устроен, кто такие боги, люди, животные и какой силой все они наделены, каково взаимоотношение между обитателями мироздания, кто кому подчинен, что может и обязан делать человек в течение своей земной жизни, что с ним произойдет после нее, и многое другое. Онтологическая предпосылочность мифа определяется, прежде всего, рисуемой в нем картиной мира. Миф тесно связан со структурой, которая проходит через разум человека, через все его существо (Campbell, 2002). Тем не менее, онтологию не может не интересовать вопрос о причинной обусловленности именно такой мифологической картины мира, а не какой-либо другой из всего множества картин мира, в каком-то смысле возможных.

Мифы не избегают противоречий и альтернативных описаний одного и того же явления. Вероятно, именно это обстоятельство объясняет поразительную живучесть древней мифологии: в ней есть в схематичном виде почти все, что свойственно миру на всем протяжении его последующей многовековой истории, причем во всей ее сложности и многозначной противоречивости. Обращает на себя внимание поразительная онтологичность содержания мифов - в них говорится о более высоких, чем человек, существах, наделенных нечеловеческими способностями, а также о стихиях, также превосходящих людей в своих качествах. Посредниками между людьми, с одной стороны, и богами вместе с различными чудовищами, с другой, выступают, как известно, герои. Возможно, частичное объяснение данного обстоятельства кроется в сильной степени зависимости древнего человека от природных стихий и его неумение адекватно понять их происхождение и мощь, превосходящую силы

XLinguae, Volume 11, Issue 2, April 2018, ISSN 1337-8384, eISSN 2453-711X 
человека, как кажется, в неимоверное количество раз (Kolychev, 2005). Однако фантазия людей перекрывала зачатки рационального мышления, без сомнения, им в определенной степени, свойственные, уже только потому, что они - люди, т.е. существа, наделенные разумом и в индивидуальной, и в коллективной его формах.

Таким образом, в древнейших представлениях разных народов отразилась сложная, разноуровневая структура Вселенной.

Анализ мифологической картины мира, рассмотрение мифа в историкокультурной динамике, позволили выявить основные свойства мифа, среди которых:

- самодостаточность, где миф является причиной и следствием, объясняет существование мира цельно;

- объективный характер, отражающий существование мифа для всех категорий людей, независимо от социального положения в обществе;

- непрерывность, определяющая вечное существование мифа во временном пространстве;

- нерасчлененность мифа, где естественный и сверхъестественный миры слиты воедино, изначально неразделены, является последствием синкретизма в культуре;

- произвольный характер, или беспредельность мифотворчества, когда миф объясняет все явления и процессы без исключения;

- символичность, предполагающая, что символы носят характер незыблемости, обозначенный в мифе.

Наиболее подробно нами рассматривается символичность как определяющая доминанта основных интерпретаций мифа в структуре познания. Проведенный анализ мифологической символики позволяет утверждать, что мифологические символы имеют древнюю историю и принадлежат к числу основных факторов и стимулов духовной жизни. Они конкретны и реальны, так как вся символика является органической частью определенной духовной культуры и передает именно эти содержания и смыслы, а не другие. Одновременно они абстрактны и иррациональны, потому что по самой своей природе воплощают и отражают продукты человеческой фантазии, закрепленной в мифологии, абстрактные и ирреальные истины, иногда доступные всеобему пониманию и предназначенные лишь посвященным.

Использование опыта осмысления мифологического миропонимания дало возможность структурирования гипотез происхождения философии, традиционно осмысливающейся в тесной связи с мифологией. Среди наиболее значимых гипотез можно выделить:

- мифогенную, где проблема происхождения философии традиционно осмысливается в тесной связи с мифологией, и первые философские учения нередко рассматриваются в качестве прямых преемников древних мифов;

- гносеогенную, где философия полагается вырастающей из накопленных знаний;

- гносеогенно-мифогенную, которая исходит из предположения о двух (соответствующих названию) источниках философской мысли;

- социогенную гипотезу, усматривающую предпосылку философии в объективно сложившихся социальных (включая экономические и политические) отношениях, переосмысленных в рационализированных формах мышления;

- софиогенную, принимающую за источник происхождения философии накопленную к тому времени мудрость.

Содержание каждой концепции предпосылочно обусловлено мифологическими образами. Разумеется, при этом существует различная степень такой обусловленности, достигающая своего максимума в мифогенной концепции философии. Поэтому древний миф в значительной мере предопределил 
онтологические схемы, прорисовываемые уже в первых философских системах древних греков. Аналогично, можно полагать существенную зависимость философской онтологии, в целом, от ее мифологического первоисточника и от соответствующей ей мифологической картины мира.

С точки зрения возникновения философии, в древней мифологии, при всем ее неразрывном единстве, различаются пласты, предпосылочные относительно философской онтологии (мифологическая картина мира) и гносеологии (мифические источники знаний). Есть и оценочно-нормативный пласт, соответствующий дихотомии добра и зла. Возможны и другие подходы к раскрытию слоистого устройства мифа. Например, в нем можно отыскать иллюзорный (собственно мифический), отражательный, фитоморфный («растительноморфный»), зооморфный, антропоморфный слои, или уровни. Ю.М. Романенко (Romanenko, 2006) утверждает о наличии в мифе теоретического и практического уровней. К приведенному перечню надо добавить еще слои поэтический (метафорический) и агармонический (сумбурный, хаотический).

Рассматривая философскую онтологию в рамках мифогенной либо гносеогенно-мифогенной концепции, необходимо отметить ряд оснований, среди которых приоритетную роль выполняет отрицание био- и антропоморфизма. Диалектическое понимание отрицания происходит с удержанием определенных сторон отрицаемого объекта, при этом они сохраняются в составе результатов и однократного, и двукратного отрицания, т.е. отрицания отрицания. В мифологии отрицание реализуется в виде дуальных оппозиций, расщепляющих целое на две противоположные составляющие. Наличие оппозиций делает миф динамичным образованием, поскольку противоположные стороны взаимодействуют, вытесняют и поглощают одна другую. Концептуализация мифологем должна была происходить не только путем синонимизации, обусловленной безоговорочным доверием к мифу. В рациональном осмыслении мифа - магистральном пути становления философии - важную роль не могла не играть операция отрицания. Критическая сторона мышления первых философов обязана была охватить в мифе и веру и с ее предметом, и то, что находится за его пределами. Изначально осмысляемая философами предметная область включала в себя очевидно константные элементы мифологем и мироздания, генезис которых в естественных условиях не мог быть созерцательно прослежен и потому принимал форму дара. Дальнейшее развитие философских знаний пошло по пути выделения всеобщего, переход к которому должен был не ограничиваться единичными объектами мифологических повествований, носящих индивидуальные имена, а иметь более широкий базис. Всеобщее лежало в основе той предметной области (включая мифологемы), от которой отталкивалась концептуализирующая мысль философов.

Развертывание критического начала в мифах создавало необходимые условия для их последующей более обстоятельной и рациональной обработки. Критика мифа развивалась по линии более строгого размежевания человека и животного, животного и растения, растения и того, что находится ниже его в иерархии творений Создателя. Все это произошло на основе и за счет развития критической функции рационализирующего мышления философов.

В качестве следующего основания философской онтологии можно выделить онтологизацию динамики и статики мифа, для которой характерно с одной стороны внутреннее развитие и изменение, с другой стороны покой, устойчивость, свойственные мифологическим сюжетам. Необходимо отметить преобладание статики в мифе, так как она непосредственно относится к сущности мифологем и к внутреннему содержанию динамических элементов

XLinguae, Volume 11, Issue 2, April 2018, ISSN 1337-8384, eISSN 2453-711X 
мифа. Совокупность динамических элементов мифа, несмотря на всю свою важность, отражает в сути своей ту же самую статику мифа. Таким путем статика переливается в динамику, а динамика - в статику. Статичность мифа соответствует устойчивости мифологического мировоззрения, подкрепленной необходимостью веры в тождество мифа и его объекта. В образовавшихся философских системах константность и устойчивость категорий прослеживается в виде неизменных форм чувственного созерцания и априорных категорий рассудка.

Онтологизация мифологических представлений происходила как следствие развертывания критической рефлексии и выдавливания из мифов биоморфных и антропоморфных его компонентов. Рационализирующая мысль, во-первых, по возможности устраняла такие «морфизмы», а во-вторых, существенно уменьшала количество персонажей мифа, причастных к творению и последующему преобразованию мира. Динамические элементы осмысливались философами диалектически (стихийная диалектика), а статические элементы представали как универсалии, сохраняющиеся во все время мировой истории.

Наличие мировых универсалий в мифе выступает третьим основанием философской онтологии, которое отражает связь между элементами мифологии и категориями философии. Это является связью между основанием и обосновываемым. Основание полагает свою противоположность, и отношение полагания как раз и свойственно связи между мифообразами и философскоонтологическими понятиями. Существенно, что такая связь в самом начале философии, т.е. вместе с процессом становления первых философских учений, разворачивалась более исторически, преодолевая мешающие ей случайности, чем в виде необходимой логики истории, с тем, чтобы предстать перед философами последующих поколений уже в несомненном логическом оформлении.

\section{Результаты исследования}

Анализ существующих гипотез происхождения философии выявляет аспект обоснованности философской онтологии мифологией. Содержание каждой гипотезы предпосылочно обусловлено мифологическими образами, где существует различная степень данной обусловленности, достигающая своего максимума в мифогенной концепции философии. Древний миф в значительной мере предопределил онтологические схемы, прорисовываемые уже в первых философских системах древних греков. Необходимо отметить существенную зависимость философской онтологии от ее мифологического первоисточника.

Методологический анализ содержания мифологической картины мира на примере финно-угорской мифологической системы позволил выявить мифологическую предпосылочность категориального ряда онтологии. В частности, на примере финно-угорской мифологической системы показано, что модель мира оформляется в образе Мирового древа как наиболее конкретного и зримого образа мироздания, символизирующего центр мира. В поэлементном строении мира выделяются Мировое древо, как символ вертикальной структуры мироздания, и Мировое яйцо, как символ потенции будущего развертывания мировой истории. Тем самым, миф соединяет пространственную и временную структуры мира. Мир во времени еще не реализовался, ему еще предназначена длительная и, видимо, неодномерная эволюция, тогда как пространственная эволюция, пожалуй, в мифе считается, в основном, завершенной.

Выявление основных свойств мифа позволило выбрать символичность в качестве приоритетного свойства. Мифологическая символика, ее анализ являются определяющей доминантой основных интерпретаций мифа в структуре культурной символики. Символ, представляя законченный текст, может быть достаточно просто выделен из своего семиотического окружения, с 
тем, чтобы войти в новый текст, не теряя при этом структурной и смысловой самостоятельности.

В процессе исследования были выявлены элементы, служащие мифологическими основаниями содержания философской онтологии, а именно: отрицание био- и антропоморфизма, наличие мировых универсалий в мифе, онтологизация динамики и статики мифа, отражающая связь между элементами мифологии и категориями философии.

Раскрытие онтологического содержания ряда мифологем, таких как культурноисторические константы Вселенной, Бога, Бездны, бытия, времени, пространства, стихии, слова, человека, позволило проанализировать соотношение мифотворчества и генезиса философии в их логической взаимосвязи, обосновать характер связи между элементами мифологии и категориями философии.

Представленные мифологические свойства, уровни развития мифологии, мифологические основания онтологии в совокупности составили систему исследования мифологических предпосылок онтологии с позиции детерминизма (Рисунок 1). 


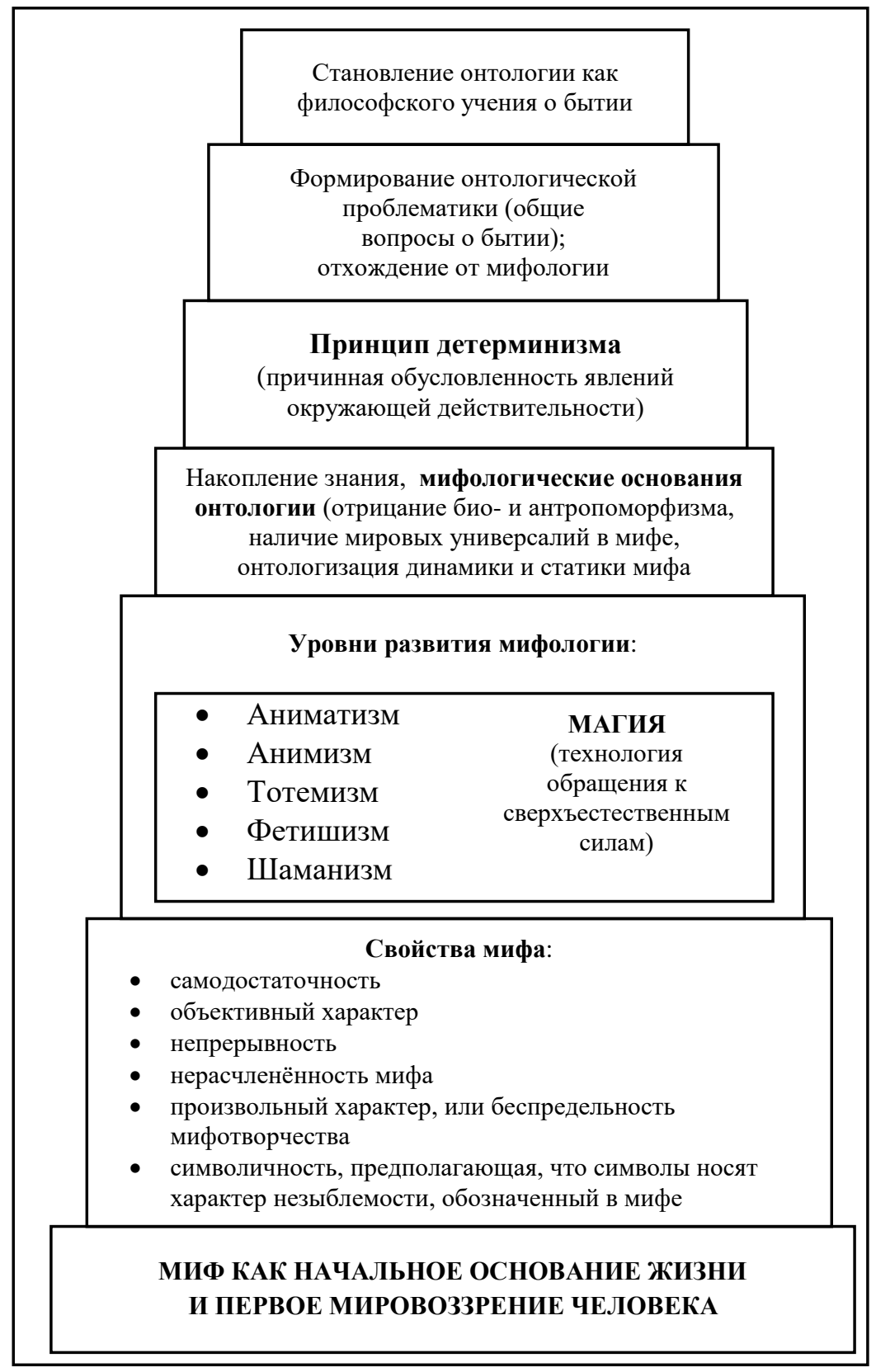

\section{Рисунок 1: Мифологические предпосылки онтологии Обсуждение}

Процесс исторического перехода от мифа к философии интересует исследователей во многих отношениях. В XX веке особое внимание привлекла символизация мифа, которая рассматривается главным средством культуры и одновременно инструментом ее критики. Центральным понятием в концепции Э. Кассирера (Cassirer, 2001) является мифологическое мышление, структуры 
которого ограничиваются от научного способа познания: вмешательству и возобновлению мифа в сфере науки лишь тогда может быть успешно положен предел, если миф предварительно осознан в его собственной сфере в смысле того, чем он интеллектуально является и каковы его интеллектуальные возможности (Cassirer, 2001). Согласно утверждению Ю.М. Лотмана (Lotman, 1994), символ является важным механизмом памяти культуры, когда переносит различные семиотические образования из одного культурного пласта в другой. При этом неменяющиеся, т.е. константные наборы символов, по мнению Ю.М. Лотмана (Lotman, 1994), в значительной мере выполняют объединяющую функцию: они осуществлят память культуры о себе и не дают культуре распасться на изолированные хронологические пласты.

Современные психосоциологи видят в анализе символических форм, созданных человеком, ключ к пониманию сущности всех общественных явлений самого человека. Системы символов в социальной психологии рассматриваются не как вспомогательное средство формирования адекватных отражательных образов тех или иных сфер общественного бытия, а как способ «самовыражения» личности и ее связи с другими людьми.

Интересные мысли относительно природы понятия «символ» изложены К.А. Свасьяном (Swassjan, 2000), отмечающим, что органичность мифа, интерферирующая в нем живой и сложной диалектикой структурных напластований, выявляет нам его символическую природу. Структурноформальный анализ мифа может разлагать его на определенное количество пластов; такое же количество пластов обнаружит в нем психологосодержательный анализ. Но взаимопроникновение всех этих аспектов, их формальная ненадежность создают совершенно особый колорит, сигнализируемый каждым из пластов в отдельности, всеми пластами вместе и, тем не менее, не классифицируемый никак в качестве еще одного пласта. Колорит этот формально анонимен; тем самым подчеркивается его принципиальная нерегистрируемость в реестре категориальных форм (Swassjan, 2000).

Мифологический символ - своеобразный язык, с помощью которого духовный мир выступает в диалог с личностью и доносит до нее свои ценности. При всей своей духовной, эстетической, этической ценности этот язык не универсален и не однозначен. Символ всегда что-то олицетворяет, содержа в себе несравненно более глубокий смысл, чем просто знак.

Каждое новое поколение не изобретает новые мифологические символы. Они передаются человеку как очень важная часть подлежащей усвоению духовной культуры. Он подготовлен к их восприятию не только воспитанием и средой, они передаются ему в качестве архетипического наследия и по архетипическим механизмам. Успех в овладении мифологической символикой зависит от того, насколько устоялось его единообразное понимание в данной общности, т.е. от социально-психологических факторов.

Процесс рационализации мифа предполагал использование иных способов и процедур мыслительной деятельности, поскольку рационализация многоаспектна. Особо можно выделить ее аналитическую составляющую, позволяющую различать объективное и субъективное. Тема рационализации мифа поистине неисчерпаема, свидетельством чему служит разрабатываемая в последнее время Е.Я. Режабеком (Rezabek, 2003) идея линейной концептуализации мифа, опиравшейся на левополушарное - недиффузное мышление.

Различные аспекты современного мифотворчества становятся предметом исследования ряда ученых, объясняя неизбежность мифотворчества в условиях расширения визуального компонента восприятия мира, обилия и мозаичности

XLinguae, Volume 11, Issue 2, April 2018, ISSN 1337-8384, eISSN 2453-711X 
информации, приводящей к созданию нужного образа окружающей действительности (Balabolina, 2005). Проводится сравнительный анализ архаического и современного мифологического сознания, утверждается взаимосвязь мифологического сознания с другими формами общественного сознания (Ivanov, 2006). Как одна из доминант мифологического сознания, выделяется этнокультурная составляющая, оказывающая большое значение на эволюцию традиционного мировосприятия. (Kaliyev, 2004).

В русле мифогенной и гносеогенно-мифогенной концепций стали появляться работы, посвящённые нахождению связей мифа древнего и современного, исследованию механизма функционирования мифа в современной культуре (Batasheva, 2014), особенностям трансформации мифологического мировоззрения в современных условиях (Vershina \& Mikhaylyuk, 2015).

Современными исследователями поднимается вопрос универсальности мифотворчества как особой формы активности сознания. В преобразованных формах миф может воспроизводиться в различных исторических и социальнокультурных условиях (Naidysh, 2017). Ряд авторов доказывает, что XX век как переходная эпоха способствует возрождению мифологического сознания, когда миф, составляя коллективное бессознательное, оказывает активное воздействие на мировосприятие человека модерна и на сферу искусства, несмотря на вытеснение мифа рационализмом эпохи модерна (Xrenov, 2011).

В. Шубин (2015) приводит доказательства неповторимости мифологического мировоззрения, выявляет ценности мифологического сознания, выделяя важнейшую - единство индивида с родом (Shubin, 2015). М. Элиаде (Eliade, 2010) отмечает живучесть мифологии, указывая, что секуляризованная и демифологизированная греческая религия и мифология сохранились в европейской культуре в связи с тем, что получили выражение в произведениях культуры и искусства (Eliade, 2010). Поразительная живучесть мифа состоит не только в его неисчерпаемости, несводимости к выделяемым частям, но и в способности приспосабливаться к радикальным изменениям в обществе и культуре. Ряд исследуемых вопросов посвящен проблемам взаимоотношений мифа и научной теории, влиянию христианских мифов на развитие естественнонаучного знания (Petrunin, 2017). Учеными делается вывод о том, что человек по своей природе нуждается в мифологии и религии, которые рассматриваются не только как формы сознания, но и своеобразные механизмы, благодаря которым сознание работает правильным образом, в связи с чем в будущем человечество продолжит создание современных форм мифов (Michelson, 2008).

Остается открытым ряд вопросов, направленных на исследование предпосылочной связи мифологии и философии, в том числе вопрос о выявлении причин, по которым не всякая мифология в исторической действительности породила собственную, соответствующую ей философию, а значит, и входящую в нее онтологию. Этот вопрос подразумевает, между тем, определение потенциальной готовности языческих мифов к тому, чтобы стать принципиальной основой несостоявшихся философских учений с их невыявленными особенностями.

\section{Заключение}

В результате проведенного исследования были проанализированы предпосылки обоснованности философской онтологии мифологическими образами, в частности, и мифологией, в целом. Какой бы гипотезы происхождения философии ни придерживались, в любом случае ее содержание предпосылочно обусловлено мифологическими образами. Разумеется, при этом существует различная степень данной обусловленности, достигающая своего максимума в мифогенной концепции философии. 
В качестве мифологических оснований онтологии выступает ряд положений, а именно: отрицание био- и антропоморфизма, онтологизация динамики и статики мифа, наличие мировых универсалий в мифе.

Миф динамичен, однако вне зависимости от исторических и социокультурных условий существования миф обладает рядом свойств, среди которых: самодостаточность, объективный характер, непрерывность, символичность, нерасчлененность, произвольный характер. Символичность выступает определяющей доминантой основных интерпретаций мифа в структуре культуры.

В статье предпринята попытка выявить онтологическое содержание мифологии в рамках ее причинной обусловленности. Проведен методологический анализ содержания мифологической картины мира, выявлена мифологическая предпосылочность категориального ряда онтологии. Проанализировано соотношение мифотворчества и генезиса философии в их логической взаимосвязи. Установлено, что определить характер присутствия мифов в бытии можно при условии исследования ряда аспектов, таких как: гипотез происхождения философии, мифологических оснований онтологии, свойств мифа, уровней развития мифологии.

Материалы статьи могут быть полезны для преподавателей и работников сферы науки и культуры, интересующихся проблемами развития культуры, философии и мифологии.

В процессе исследования возник ряд вопросов, что определяет необходимость продолжения исследования поиска новых подходов и методов в изучении проблем мифологической предпосылочности онтологии.

\section{Bibliographic references}

BALABOLINA, T.A. 2005. Modern myth-making: social and philosophical analysis: PhD Thesis. Khabarovsk: Publishing house of the Khabarovsk state University.

BATASHEVA, A.C. 2014. Myths in modern culture: positive and negative role. In: Young scientist, vol. 8, pp. 743-746. ISSN 2072-0297.

VERSHINA, V.A. - MIKHAYLYUK, A. V. 2015. Myth in modern culture. In: Gileya. Scientific Herald, vol. 95, pp. 234-238. ISSN 2076-1554.

IVANOV, A.G. 2006. Archaic and modern mythological consciousness: social and philosophical aspect: PhD Thesis. Voronezh: Publishing house of the Voronezh state University.

CASSIRER, E. 2001. The Philosophy of symbolic forms. Vol 2. Mythological thinking. Saint-Petersburg: University book. ISBN 5-7914-0023-3

KALIYEV, A.Y. 2004. Ethnic and cultural status of mythological consciousness: Genesis, functioning and evolution of the traditional worldview on the example of Mari mythology: PhD Thesis. Cheboksary: Chuvash state University.

CAMPBELL, J. 2002. The myths in which we live. Kyiv: Sofia. Moscow: Gelios. ISBN 5-344-00255-6.

CASSIDY, F.H. 2003. From myth to logos: the rise of Greek philosophy. SaintPetersburg: Aletheia. ISBN 5-89329-628-1.

KOLYCHEV, P.M. 2005. Understanding the myth. Saint-Petersburg: Publishing house of St. Petersburg University . ISBN 5-288-03834-1.

LOSEV, A.F. 1994. Myth. Number. Essence. Moscow: Thought. ISBN 5-244-007475 .

LOSEV, A.F. 1995. The problem of symbolism and realistic art. Moscow: Art. ISBN 5-210-02247-1.

LOTMAN, Yu.M. 1994. Lotman and the Tartu-Moscow school of semiotics. Collected papers. Moscow: Gnosis. ISBN 5-7333-0486-3.

XLinguae, Volume 11, Issue 2, April 2018, ISSN 1337-8384, eISSN 2453-711X 
MICHELSON, O.K. 2008. Interpretation of mythological consciousness of modern man in philosophy and psychology of religion the XX century. In: Journal of contemporary foreign philosophy "Chorus", vol. 3, pp. 51-60. ISSN 2070-805x.

NAIDYSH, V.M. 2017. Mythmaking in the activities of consciousness. In: Philosophy Questions, vol. 5, pp. 26 - 34. ISSN 0042-8744.

NAIDYSH, V.M. 2002. The philosophy of mythology. From antiquity to romanticism. Moscow: Gardariki. ISBN 5-8297-0115-4.

NOVAKOVA, K. 2015. Ethics and Ethic Codex in the Teaching Process. In: Procedia - Social and Behavioral Sciences, vol. 174 pp. 2390-2394. ISSN 1877-0428.

NOVAKOVA, K. 2011. Tradicne sposoby prepravy deti v Europe a podoby ich sucasnej revitalizacie. In: Ethnologia Europae Centralis : Journal of Ethnology of Central Europe. Brno: Jan Soucek. vol. 10, pp. 55-63. ISBN 978-80-903911-1-6. ISSN 1210-1109

PETRUNIN, Y.Y. 2017. Lapis philosophorum, artificial intelligence и perpetuum mobile: evolution of relations between myth and science. In: Questions of philosophy, vol. 3, pp. 42 - 51. ISSN 0042-8744.

REZABEK, E.J. 2003. Mitomycine. Cognitive analysis. Moscow: URSS. ISBN 5354-00174-9.

ROMANENKO, Yu. M. 2006. The Ontology of myth. Saint-Petersburg: Publishing house of St. Petersburg University. ISBN 5-288-04177-6.

SWASSJAN, K.A. 2000. The Problem of symbol in contemporary philosophy. Blagoveshchensk: Publishing house BGK them A. Baudouin de Cortenay. ISBN 5-80157-220-1.

FREUD, Z. 1992. Psychoanalysis. Religion. Moscow: Renaissance. ISBN 5-83960095-4.

FREUD, Z. 2003. Interpretation of dreams. Minsk: Medley. ISBN 985-483-089-6.

XRENOV, N.A. 2011. Myth and artistic consciousness of the XX century. Moscow: Canon ROOI "Rehabilitation". ISBN 978-5-88373-267-5.

SHUBIN, V. 2015. The values of mythological consciousness. In: Scientific-cultural journal, vol. 3, pp. 42 - 51. ISSN 1814-0149.

ELIADE, M. 2010. Aspects of myth. Moscow: Academproject. ISBN: 978-5-82911125-0.

JUNG, C.G. 1991. The Archetype and the symbol. Moscow: Renaissance. ISBN 57664- 0462-X.

Words: 4766

Characters: 39143 (21,75 standard pages)

Assoc. Prof. Svetlana V. Potapova, PhD

Department of Humanitarian Education and Sociology

Almetyevsk State Oil Institute

2 Lenin Street,

423450 Almetyevsk,

Russia

uch-agni@yandex.ru

Assoc. Prof. Irina Yu. Danilova, PhD

Department of Humanitarian Education and Sociology

Almetyevsk State Oil Institute

2 Lenin Street,

423450 Almetyevsk,

Russia

danilova.agni@mail.ru 
Assoc. Prof. Valeriy I. Prasolov, PhD

Department of Risk Analysis and Economic Security

Financial University under the Government of the Russian Federation.

49 Leningradsky prospect

125993 Moscow

Russia

VIPrasolov@fa.ru

Assoc. Prof. Elena V. Makarova, PhD

Department of Physical Education

Ulyanovsk State Agrarian University named after P.A. Stolypin

1 Bulvar Novy Venets

432017, Ulyanovsk

Russia

vasilevna73@mail.ru

Prof. Nina I. Kryukova, Dr.

Department of State-Legal and Criminal Law Disciplines

Plekhanov Russian University of Economics

Moscow, Russia

36 Stremyannyi Pereulok Str.

115093 Moscow

Russia

ninari68@mail.ru 